\title{
A Brief Rationale for a New Journal in the Field of Higher Education
}

\author{
Dan Chiribucă \\ Centre for University Development and Quality Management, \\ Faculty of Sociology and Social Work, \\ Babeș-Bolyai University, 1. M. Kogălniceanu St. Cluj-Napoca, Romania \\ dchiribuca@socasis.ubbcluj.ro
}

Undoubtedly, higher education has become a sector with a major role in the economic and social development, much more important than the position reflected by the rank in a hierarchy calculated on the basis of statistical indicators such as GDP, number of employees or number of enrolled students.

The societal importance of the higher education system is given not by the volume of financial flows, but by the fact that universities are public good institutions, essential as education agencies, knowledge producers and major cultural resources (Rumbley et al 2014).

Beyond generic value statements, from a real world, mundanegrounded point of view, higher education has become a worldwide enterprise, a very complex one in terms of organization, with multiple and quite often self-contradictory objectives/goals, highly autonomous and at the same time dependent upon public control and regulation, with various stakes and heterogeneous stakeholders. 
6・ Journal of Research in Higher Education • Vol. I, No. 1

A natural result of these developments is the steady increase of the need for data, analyzes, theoretical and empirical research. Illustrative for this demand, and also for the way in which the higher education academic field assumes and nourishes its own growth and development is the steep raise of higher education journals in the last years. Inventories carried out by Boston College Center for International Higher Education (CIHE) recorded 280 journals in 2014 with 89 morethan in 2006. It deserved to be noticed that the 2014 listing excluded more than 200 Chinese journals considered as being too local and with little impact beyond the sponsoring university (Rumbley et al 2014).

In such a fast growing market with so many new competitive actors, is it worthy to invest resources, even if that means mostly time and energy, for a new journal in the field of higher education? I firmly believe that the answer is yes.

Arguments behind this conviction are numerous and anchored in multiple plans. Some are related to the publishing realities, some to the substantial features and dynamics of the higher education system. As concerns the publishing, it is true that worldwide there are already so many valuable and influential journals that the opportunity and desirability to launch a new one should remain questionable. But sheer number is not synonym with equally distributed. Almost half of the journals listed by CIHE are published in four countries (USA, UK, Japan, China) and from 61 journals published in European countries, only 4 are in Central and Eastern Europe.

An uneven distribution of journals by countries does not mean anything in what concerns the potential bias in content coverage. Globalization and technology blurred the spatial boundaries and sealed the emancipation of knowledge flows. But the fact is that, despite an undeniable process of convergence, higher education systems remain a very heterogeneous and complex reality, a mix of universal invariants and very specific and local issues, of influences and dependencies exerted equally by global trends and local regulations. The diversity and range of relevant topics, approaches, research data and analyses are too vast and still too country-dependent to be comprehensively covered by journals published abroad, in remote countries. The white spots on the map of journals' regional belonging are doubled by a propensity related to content. A meta-analysis carried out recently on quality management 
research in higher education institutions pointed out a predominance of theoretical articles in educational journals (Tari \& Dick 2016).

There is no need to highlight the importance of conceptual and theoretical debates for the academic establishment and status of such a practical field as higher institution studies certainly is. But also, for policy and decision makers, as well as for all stakeholders who form the constituency of believers in the New Public Management narratives, analyses grounded in empirical research and tools for measuring the performance of universities are more valuable and necessary now than any time before. Consequently, the emergence of new journals in the field of higher education is rather an answer to institutionalized expectations than an academic fad.

As regards the dynamics of the higher education system, there are many drivers that constitute, on the one hand, challenges and constraints for contemporary higher education and, on the other hand, structural antecedents responsible for an entire set of systemic change and remodeling processes.

Some of these drivers are related to transformations and dynamics caused and assumed as elements of convergence generated by policies whose finality and stake transcend the education system. A relevant example is the Bologna process, which has initiated a convergence route for the European higher education system, with the manifest objective of ensuring comparable standards and quality of higher education qualifications.

Another part involves broader, cultural, economic, societal, structural transformations that have sources outside universities, but directly influence universities. There are changes extremely diverse in content and range that cover very different levels of the social environment (Locke \& al 2011): demographic changes, technological innovations and developments, globalization and market orientation of educational processes and activities, redefining social welfare priorities. From the same category, but distinct through the major impact on the roles assumed by the university, are the fundamental changes in advanced economies that go from mass production and linear transfer relationships to more open, more interactive, knowledge driven, innovation-based systems. It is not the first time in history when universities find themselves in the flow of such transformations. Modernity and the industrial revolution have remodelled the university, 
8 J Journal of Research in Higher Education • Vol. I, No. 1

transforming it from a knowledge storehouse into a knowledge producer.

Nowadays, universities are again obliged to reorganize research, new technological developments require interdisciplinary approaches, - to adapt their educational mission and methods, to reconsider how they develop and participate in knowledge transfers, including interactions and networks with industries and the community (Youtie, Shapira 2008). In the knowledge society, beyond the main roles of carrying out a more or less conventional research, and of a quality provider of educational services, the university is a hub and promoter of innovative knowledge.

The possible routes to be followed are neither clear nor predefined because in such a fluid social reality the destination points are constantly moving. The fact is that the classic Humboldtian model competes with entrepreneurial models which, besides an understandable focus on financial return of the university enterprise, involve active engagement in economic and social development by capitalizing on research, know-how transfer, spinoffs, cooperation with economic development agencies, a whole new direction recently coined as third stream activities. It is a competition further fuelled by the fact that innovations are now emerging from problem-oriented research that transcends the boundaries of traditional disciplines; energy, the environment, health, the aging society, poverty, are just a few possible examples. Transdisciplinarity has become an almost mandatory feature, which inherently questions the traditional segmentation of the university in clearly circumscribed and scientific fields assimilable to faculties.

Last but not least, another set of drivers derives from the fact that universities have been placed in a relatively new ideologically and narrative context. It is a frame established and built around a new set of values at its core: competition, performance, public accountability, environmental sustainability, and so on.

All these factors are influential and challenging but my belief is that the biggest case for the higher education system is none of them or others, but the relationship between university and change. One of the main dimensions of the traditional culture of the university, especially of a public university, is the autonomy against external influences. It has always been a protective quality for the independence of research and 
freedom of thought, but also a deterrent of change. The culture of public universities is characterized by a strong resistance to change (Casablancas-Segura \& Llonch 2016).

From the very beginning of the university as a public institution, the control of academics over their institution was a main tenet of the university organization and reluctance to lose this control remains till today a main driver of its internal policy. It is a conservatism cultivated by an almost universal rule of fixed-term, rotating, internal appointments to management positions. Consensus decision making by a board of academics is somehow fundamentally incompatible with strategic management involving long-term planning and objectives (Deem 2006). I have no doubts that no journal, old or new, or any number of research grounded articles would change that anytime soon. But I am also convinced that more professional information, more analyses of contemporary trends, more empirical researches and analyses of existing data, new public spaces used for problems identification and for debating solutions to these problems, looking for effective ways to use local resources in order to successfully participate in global competitions, as well as so many other possible examples, could not impend but only contribute to the progress of higher education as a system, practice and academic science. And I firmly believe that all of these are enough reasons to initiate and support the project of a new journal in this field. 
10 • Journal of Research in Higher Education • Vol. I, No. 1

\section{References}

Casablancas-Segura, C., \& Llonch, J. (2016). "Responsive and proactive stakeholder orientation in public universities: antecedents and consequences.", Higher Education, 2(72): 131-151.

Deem, R. (2006). "Changing Research Perspectives on the Management of Higher Education: Can Research Permeate the Activities of Manager-Academics?" Higher Education Quarterly, 60(3), 203228.

Juan José Tarí, Gavin Dick, (2016). “Trends in Quality Management Research in Higher Education Institutions", Journal of Service Theory and Practice, 26(3): 273-296.

Locke, W., Cummings, W. K., \& Fisher, D. (Eds.). (2011). Changing Governance and Management in Higher Education: The Perspectives of the Academy (Vol. 2). Springer Science \& Business Media.

Rumbley, L. (2014). Higher Education: A Worldwide Inventory of Research Centers, Academic Programs, and Journals and Publications. Lemmens Media.

Youtie, J., \& Shapira, P. (2008). "Building an Innovation Hub: A Case Study of the Transformation of University Roles in Regional Technological and Economic Development", Research Policy, 37(8):1188-1204. 